\title{
FRIES: FIRST RESPONSE INTERACTIVE EMERGENCY SYSTEM FOR THE VISUALLY AND HEARING IMPAIRED
}

\author{
Wafa Elmannai, Yi Wang, Eltion Aliaj, Ahnaf Chowdhury, Rishamdeep Khehra, Dilara Yildi and Solange Soria
}

\begin{abstract}
It is very challenging for the visually and hearing- impaired people to react properly in case of a fire than the none- visually and hearing impaired. In addition, there is a lack of the current emergency response systems in the market that cater to the needs of visually and hearingimpaired people. Most of the current methods are expensive and unreliable while $90 \%$ of visually and hearing-impaired people live in developing countries. Therefore, we proposed a new emergency system called The First Response Interactive Emergency System (FRIES). This system provides all the emergency needs of hearing and visually impaired individuals when they are awake as well as asleep in case of a fire, carbon monoxide, and natural gas leak. It will also notify the emergency personnel and their caregivers. The cost of this system is very affordable. Our system consists of a microcontroller, which will be connected to the LED lights, gas sensors, smoke sensors, fire detector, speaker module, WIFI module, vibrating motors, and LCD display. All sensor data is simultaneous transmitted between the microcontroller and sensors. Our promising results showed that this system can be a complete emergency detection solution to provide safety for the visually and hearing impaired.
\end{abstract}

Keywords-Fire detection, visual impairment, hearing impairment, emergency response system, sensors \& safety.

\section{INTRODUCTION}

$F_{t a n}^{i n}$ re detection systems are playing a significant role in terms of safety and life protection. Back to 50 years ago, automatic fire detection was hardly provided in properties comparing to today [1].

\footnotetext{
W. E. Author is with Manhattan College, Bronx, NY 10471 USA (corresponding author, phone: 718-862-7271; e-mail: welmannai01@manhattan.edu).

Y. W. Author is with Manhattan College, Bronx, NY 10471 USA (email: yi.wang@manhattan.edu).

E. A. Author is with Manhattan College, Bronx, NY 10471 USA (email: ealiaj01@manhattan.edu).

A. C. Author is with Manhattan College, Bronx, NY 10471 USA (email: achowdhury01@ manhattan.edu).

R. K. Author is with Manhattan College, Bronx, NY 10471 USA (email: rkhehra01@manhattan.edu).

D. Y. Author is with Manhattan College, Bronx, NY 10471 USA (email: dyildiz01@ manhattan.edu).

S. S. Author is with Manhattan College, Bronx, NY 10471 USA (email: ssoria01@ manhattan.edu).
}

Numerous lives have been lost due to these fire accidents within the buildings and properties. The factors behind these cases are human mistakes, short circuits, smoke/gas leaking. However, the main reason behind the fire results is the lack of early detection [2].

Almost 17,500 people who get injured and 3,400 people die yearly because of the fire incidents according to the Federal Emergency Management Agency's (FEMA) report [1]. Fire is a disaster that can happen anytime and anywhere in the world due to natural reasons or accidents [3]. Therefore, immediate rescue and response is needed. We have fire alarm systems that warn us and could help avoid injuries or deaths. However, the situation is more dangerous for people who are visually impaired and hearing impaired. It is completely difficult for disabled people to escape in case of fire [4]. Currently, there is a lack of research work that addresses the needs of the disabled people. Most researchers in the fields of developing assistive devices focused on mobility rated issues for disabled people. However, very few published works tackled the fire detection related issues for disabled people. Therefore, the need of an assistive and responsive system that is able to save disabled people lives in case of fire or gas leaking is well-established. They need a special warning system and assistance due to their disability, yet there is no emergency response system in the market that can fully assist individuals who are visually impaired and hearing impaired in case of a fire, carbon monoxide, and natural gas leak. Most existing warning systems are very expensive and nonreliable whereas almost $90 \%$ of disable people live in developing countries and they are from low-income groups [5]. An emergency system that provides fast detection, immediate warnings and ultimately alerts the emergency authorities, as well as the listed emergency contact of the individual is the main concern of this paper. To this end, an affordable warning system for the visually impaired and hearing impaired is proposed. This system is called The First Response Interactive Emergency System (FRIES). FRIES is an emergency system that warns and assists individuals regardless of their needs and even goes as far as alerting not only emergency personnel but also their caregivers.

\author{
Copyight Authors
}

ISSN (Print): 2204-0595

ISSN (Online): 2203-1731 
FRIES will provide a safe living environment for individuals with visual and hearing disabilities.

Fig. 1 shows the objectives of the proposed FRIES. The objectives are life safety, fast detection, immediate warning system, emergency personnel alertness and affordable. In order to provide fast detection, our system will operate using an efficient microcontroller and custom-made power board. Immediate warning system; upon program execution, all actions will run stimulatingly: the LED's will light up, the speaker will inform the occupant of the emergency, the LCD screen will display emergency instructions to the occupant, vibration motors located in every bed and couch which will assist in a fast warning. To assist the occupant with the emergency preparations, the microcontroller system will trigger a signal to the appropriate module to alert all emergency personnel at the first sign of a fault. In addition, the system will send a message to the emergency response switchboard alerting them. The system will also send a message to the listed emergency contact of the occupant. The emergency alert system is affordable and can be installed in any housing and apartments to give the people with visual and hearing impaired the sense of independence.

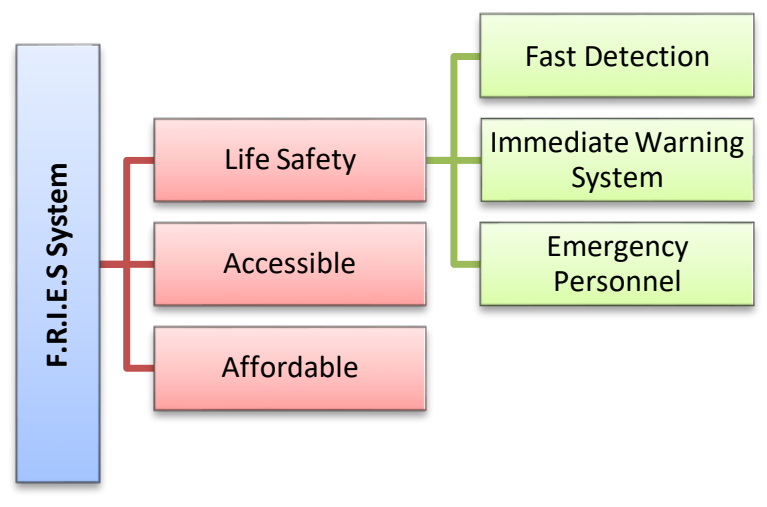

Fig. 1. Objectives of the Proposed FRIES.

The main contribution of this work is as follows: 1) We proposed a new affordable emergency system for the visually and hearing impaired; 2) This system can provide comprehensive first response emergency needs in case of a fire, carbon monoxide, and natural gas leak; 3) The system is validated and verified through software/hardware co-design and implementation.

This paper is organized as follows: Related Works in section 2; Proposed Work and Software/Hardware Codesign is explained in section 3. Experiment, including

Copyright $\odot$ Authors experiment setup, results, testing and real-world scenario are discussed in section 4. Comparison and Discussion are presented in Section 5. Cost Estimation is presented in section 6 . Section 7 will be the conclusion.

\section{RELATED WORK}

Although researchers are continuously working to improve fire detection systems and increase the level of safety, these systems are applicable only to insight people. In addition, very few researches have addressed this area specifically for disabled people. Therefore, we will present a few research papers and commercial designs that provided safety responsive systems for them.

We came across recently published works that specifically introduced a fire detection system for disabled people. Kong et al introduced two models based on deep learning-based object detector to detect fire for the visually impaired [1]. The two models are very similar in schema with slightly difference in complexity. The accuracy of object detection and features learning is $90 \%$ for both models. The difference is the recall for the first model is $85 \%$ at 33 FPS and $61 \%$ for the second model at FPS. This system is limited to visually impaired people. The system is also a non-practical system due to the delay time and complexity of deep learning.

Michihiko et al introduced a robot that alerts users to the sounds of fire or smoke detectors inside the property [6]. The authors were inspired by the assistant dog's behavior for above mentioned events. The system is composed of bumper sensors to pump or tickle the user in case of urgent as well as it includes wheels at the bottom of the kit for mobility purposes. The system is basically depending on the use of TurtleBot kit. We believe that system would be able to serve in a small room or space. The system is not reliable due to many limitations; one of them is that its appearance is not applicable for daily use. In addition, the kit would consider as an obstacle for a disabled user. Furthermore, the system is proposed only for hearing impaired people.

Ciabattoni et al introduced a notification system for visually and hearing-impaired people which is connected to a mobile phone [7]. The purpose of this system is to provide the user with voice and text messages in case of a hazardous situation. The system consists of a wall smart plug, ZIPATO gateway, a 
smoke sensor, a flood sensor, a CO sensor, and cloud server. The communication is done through Zwaveprotocol. The notification process is done only through the cellphone. In case the user is not carrying his phone or if he/she is away from the cell-phone, the user will not be alerted.

An integrated paraclete with an alert circuit was introduced in [8] to alert hearing-impaired users for threats such smoke or fire. This circuit includes a number of alarm units, lights sources, antenna, vibrators, and battery. Sequence of vibrations and illumination will be produced based on the type of threat. However, this system is not reliable in term that the percentage of wearing the paraclete all the time is very low. In addition, it is very hard for the user to distinguish different vibration patterns.

There are a number of solutions in the market for addressing the needs of hearing and visually impaired in case of fire. Some of the solutions are as follows:

Lifetone HL is a fire alarm clock that responds to smoke alarm and aids in waking up visually or hearing-impaired people at in case of fire detected [9]. A number of researches claimed that people do not wake up at night to their smoke alarm and this could cost them their lives as the very disastrous fire incidents occur at night. Lifetone uses technology such as audible alerting, audible announcing, tactile alerting, and visual notification to wake up people in case of fire. Audible alerting uses low frequency $(520 \mathrm{~Hz})$ to wake up the person as low frequencies travel longer distances and there is less energy loss between material. Audible announcing uses the speaker to deliver a message "Get Out" to the sleeper so that they could wake up and exit the place. However, false detection would cause an unnecessary evacuation. Tactile alerting is a vibrator that comes with the fire alarm clock. The vibrator needs to be in proximity to perform the function as intended which is to wake up the sleeper in case of a fire. On the other hand, the visual notification displays an orange screen on the alarm clock with the message "Fire" on it.

Bellman Visit Pager is a device that alerts the hearing and visually impaired individuals by sending vibrating signals [10]. However, the pager needs to be on the person at all times in order for this to work. This can be achieved by either clipping the pager to a cloth or carrying in the pocket. Pager works in conjunction with the FireSafe system to notify user of fire in the workspace and residential and commercial accommodation. The problem

Copyright $\odot$ Authors with this design that it can easily slip of the user's clothes. In addition, it is uncomfortable to be worn at night, especially for disabled people.

Ei176 Smoke Alarm System is proposed for deaf and hearing-impaired individuals [11]. This smoke alarm includes a xenon strobe to visually indicate that there is a fire. The strobe is of high intensity. The kit also has a vibration pad so that if the fire occurs at night, the deaf person could wake up. Apart from this, there is an optical smoke alarm in the kit. When the smoke alarm is activated, the xenon strobe light and vibration pad are triggered and perform the intended function which is to aid the hearing-impaired individual. There is red and green light on the strobe. The green light shows that there is power for the system. However, when the system is using battery power, the red light will flash every 40 seconds and there will be no green light. In this system, there is a backup battery that can power the system up to 7 days after a failure. This system is best suitable for hallways, living rooms, dining rooms, and bedrooms. Deaf and hearing-impaired people benefit from this as the strobe light which will alert them that there is fire and they should take the necessary steps to get out of the place of incident. In addition, the vibrator pad will aid in waking up the deaf person at night as they cannot see the strobe lights when asleep. Once they are awake, they can see the strobe light and their life can be saved.

The above-mentioned commercial systems partially adhere to the needs of visually and hearing impaired. However, none of these systems fully satisfy the needs of the user. Even though Lifetone HL assists hearing and visually impaired individuals, it only does so when they are physically proximate in order to feel the vibrations coming from the nightstand. If a person rolls over at night to the other side of the bed, they will not be able to feel the vibrations and this could lead to a catastrophic incident. Thus, even after the hearing and visually impaired person are aware of a fire, they need to call the emergency personnel. This could cause a problem, since the blind person cannot see and the deaf will not be able to communicate via phone. In an emergency, their priorities should be to get out of the place of an incident rather than slowly finding a way to contact emergency personnel.

Pager has to be on a person at all times. In case a hearing or visually impaired individual forgets to wear their pager, they are in a situation that could cost them their lives. Lastly, Ei176 Smoke Alarm System is limited in use to hearing impaired individuals. 
IT in Industry, vol. 8, no.2, 2020

In order to overcome the limitations, the proposed FRIES provides all the emergency needs of hearing and visually impaired individuals when they are awake as well as asleep. Our system will protect these individuals in case of fire, carbon monoxide leak, and natural gas leak. Not only that, it will also contact emergency personnel by calling 911 and their caregivers.

\section{Proposed Work And Hardware/Software DESIGN}

The nature of our system is to cater to the basic needs of individuals with disabilities during an emergency. Thus, our aim is to produce a system that is affordable to the visually and hearing-impaired people. Therefore, we propose a multi-sensor framework that integrates a number of sensors that send and receive signals from and to microcontroller.

\section{A. System Architecture and Behavioral/Functional} Decomposition

The system consists of a microcontroller, smoke detector, carbon monoxide detector or natural gas detector, vibration motors, LEDs, speaker, LCD display, WIFI module, and power supply. The system architecture is shown in Fig 2. The main contribution is to control all the sensor data and produce continuous instructions that seek the required behavior. The main function of the microcontroller will be to receive data from the connected sensors. The hardware will work flawlessly with the software and efficiently perform all the necessary tasks to save lives.

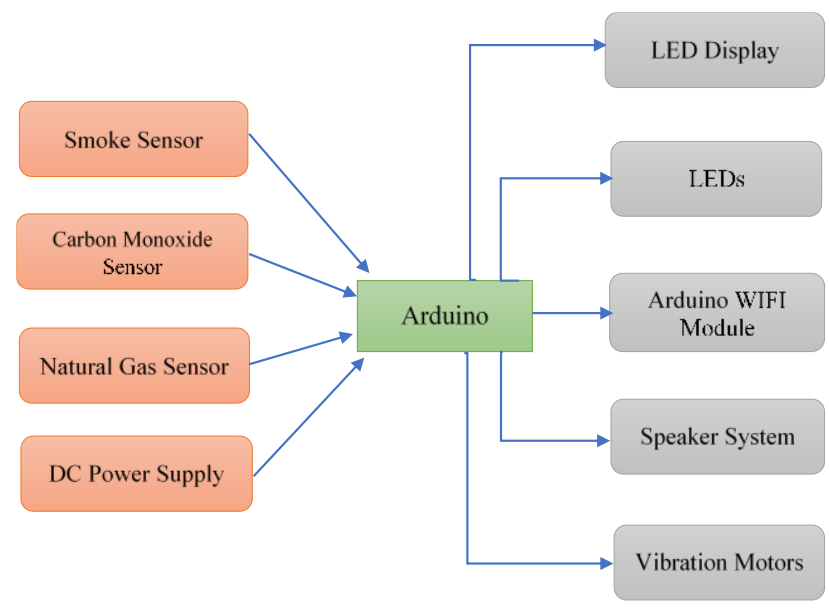

Fig. 2. The System Architecture for FRIES
Published online 07-August-2020

The main component of the system is the microcontroller which we have chosen an Arduino Uno Microcontroller, where the specifications can be seen in Table I. Arduino Uno is an open-source microcontroller board that provides a low-cost solution to interface between highlevel software and our emergency system hardware. This board is grounded on ATmega328 chip, which has 14 digital input/output pins. Among them, 6 can be used as PWN outputs, and 6 analog inputs. Compare to Raspberry $\mathrm{Pi}$, the cost of Arduino is $35 \%$ cheaper [12, 13, and 14]. Besides, Arduino is better for real- time applications. In our emergency system, Arduino can respond to multiple sensor readings in real-time very easily. In addition, although Raspberry Pi is more robust and powerful as a single board computer, Arduino can fully meet the requirements of our system. Besides, Arduino provides the flexibility of executing code directly with no operating system overhead. The primary task of the microcontroller is to receive the data in terms of signals and respond with instructions. Error can be detected from any of the sensors. The other input is the 9-volt Battery. The outputs are going to be the power to turn on LED's and the vibrating motors. In addition, the signals will be sent to the LCD, speaker, and the sensors as feedback.

Upon detection from any of the listed sources, the microcontroller will automatically begin running its program. As shown in Fig 3, the program will be started as turning on the red LEDs to signify a dangerous situation as well as flash the white LEDs repeatedly to mimic an eye-piercing strobe light. As the lights are on and flashing, an action message will be displayed on the LCD screen of the current situation in the apartment such as "Danger please EXIT!", this will help the hearingimpaired individuals significantly along with vibrating motors in beds and couches in case they are sleeping.

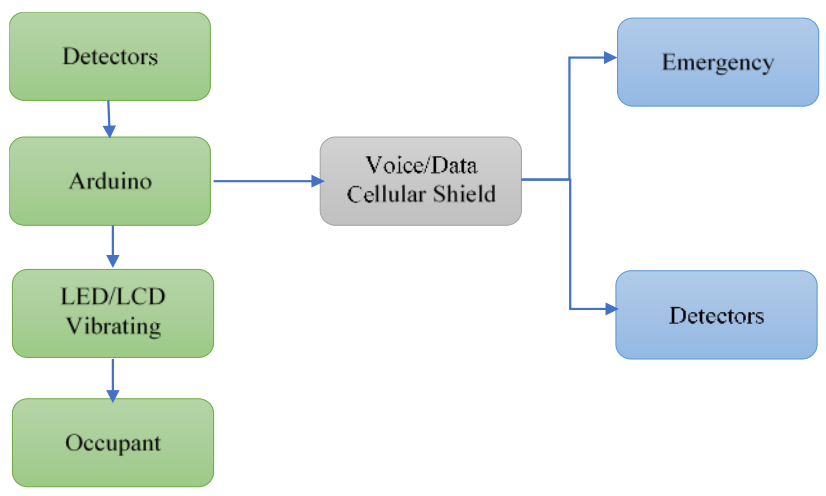

Fig. 3. Behavioral/Functional Decomposition of the Proposed System 
IT in Industry, vol. 8, no.2, 2020

For the visually impaired individuals, we install speakers that acoustically broadcast the message throughout the premises as well. To assist in emergency preparations, the microcontroller is equipped with a connectivity module that is the WIFI module which is responsible to send text messages to emergency personnel that includes address, situation of the occupant and condition. This module will be responsible to inform the occupants' caregivers or list emergency contact as well.

Table I Arduino Microcontroller

\begin{tabular}{cc}
\hline \hline Module & Ardumo Uno \\
\hline Input & $\begin{array}{c}\text { Binary Signal from Detectors (sensors) } \\
\text { (0 indicates systemis nomal, } 1 \text { indicates fault in system) } \\
\text { 9V Battery }\end{array}$ \\
Output & $\begin{array}{c}\text { Binary Signal to the Sensors } \\
\text { Binary Signal to the Speaker } \\
\text { Power to tum on LEDs }\end{array}$ \\
Function & $\begin{array}{c}\text { Power to tum on Vibration Motor } \\
\text { The Arduino is a microcontroller with its primary task to } \\
\text { receive the instruction and act onit withno hesitation. }\end{array}$ \\
\hline \hline
\end{tabular}

For the hearing-impaired individuals, we connect the system to an LCD (Liquid Crystal Display) display. The function for the LCD is: the screen will receive an analog signal from the Arduino microcontroller and convert it into a readable text. Displaying "Danger Gas Leak, please exit the building", as an example. This will ensure that the occupant will be well informed of the current situation in their dwelling. The specifications of such LCD display can be seen in Table II.

Table II Lcd Display

\begin{tabular}{cc}
\hline \hline Module & LCD \\
\hline Input & Analog Signal from Arduino \\
& 9V Battery \\
Output & Text \\
Function & The LCD screen will receive the analog signal fromthe \\
& Arduino microcontroller and convert it into rea dable text \\
\hline \hline
\end{tabular}

An efficient emergency alert system needs to have strategically placed LEDs (Light Emitted Diode). These LED bulbs will receive the power form the Arduino microcontroller and will display its intensity based on the power level being delivered. Our only input for the LED is the DC power coming directly from the Arduino microcontroller. The outputs would be the bright red light for the red LEDs to signify emergency and the white LEDs will be constantly flashing to mimic the eyepiercing strobe lights. The specifications for the LEDs can be seen in Table IV. The white LEDs will also be placed
Published online 07-August-2020

on every exit just like the speaker, so the occupant can exit their home safely.

The visually impaired occupants of the dwelling will benefit from the speaker module, as seen in Table III. The

function of the speaker is to receive an analog signal from the Arduino microcontroller and convert it into a recognizable sound. The input signal will be in binary that is coming from the microcontroller. The speaker is placed on every exit so the occupant can follow the sound to exit the building safely.

Table III Speaker

\begin{tabular}{|c|c|}
\hline Module & Speaker \\
\hline Input & Analog signal from Arduino \\
\hline & $9 \mathrm{VBattery}$ \\
\hline Output & Sound \\
\hline Function & $\begin{array}{l}\text { The speaker will receive the analog signal from the } \\
\text { Arduino Microcontroller and convert it into recognizable } \\
\text { sound }\end{array}$ \\
\hline
\end{tabular}

Table IV LEDS

\begin{tabular}{cc}
\hline \hline Module & LED \\
\hline Input & 5V DC Power from Arduino \\
Butput & $\begin{array}{c}\text { Bright Red Light for Red LED's } \\
\text { Flashing White Light for White LED's }\end{array}$ \\
Function & $\begin{array}{c}\text { The LED bulb will receive the power from the Arduino } \\
\text { Microcontroller and will display its intensity based on the } \\
\text { powerlevel being delivered }\end{array}$ \\
\hline \hline
\end{tabular}

In Table $\mathrm{V}$, we can see the specifications of the vibration motor. The function of the vibration motor is to receive 5volts from the Arduino microcontroller and in return the motor will rotate at 11,000 RPM causing the vibration. The only input for the motor is the 5-volt DC power from the Arduino. The only output is the motor rotation of 11,000 RPM. This will ensure that the sleeping occupant on the couch or bed will be able to wake up and be aware of the current emergency situation at hand.

Table V Vibrating Motor

\begin{tabular}{cc}
\hline \hline Module & Vibratung Motors \\
\hline Input & 5V DC Power from Arduino \\
Output & 11,000 RPM \\
Function & $\begin{array}{c}\text { The Vibrating Motor will receive } 5 \mathrm{~V} \text { from the Arduino } \\
\text { Microcontroller and in tum will rotate at } 11,000 \mathrm{RPM} \\
\text { causing a vibration }\end{array}$ \\
\hline \hline
\end{tabular}


IT in Industry, vol. 8, no.2, 2020

No emergency alert module would be complete without notifying the emergency personnel of the current emergency and needed assistance. Therefore, an ESP8266 WIFI module is included. As seen in Table VI, the function of the ESP8266 WIFI module is to receive the analog signal from the Arduino microcontroller and transmit a message to emergency personnel as well as a text to the emergency listed contact. The WIFI module receives the binary input from the Arduino directly and in exchange will immediately dispatch at text.

\section{Table VI ESP8266 Wifi Module}

\begin{tabular}{cc}
\hline \hline Module & ESP8266 Wifi Module \\
\hline Input & $\begin{array}{c}\text { Analog Signal from Arduino } \\
\text { 9V Battery }\end{array}$ \\
$\begin{array}{c}\text { Output } \\
\text { Function }\end{array}$ & $\begin{array}{c}\text { Analog Voice and Text transmission } \\
\text { The ESP8266 WIFI Module will receive the analog signal } \\
\text { from the Arduino Microcontroller and transmit a text to } \\
\text { emergency personnel as well as a text to the emergency } \\
\text { lie3zsted contact }\end{array}$ \\
\hline \hline
\end{tabular}

To provide the needed services, the sensor data needs to be controlled and manipulated in appropriate way. The functionality of the system is decomposed into three parts: hardware, software and execution, as shown in Fig 4.

\begin{tabular}{|c|c|c|}
\hline $\begin{array}{l}\text { Microcontroller } \\
\text { Sensors } \\
\text { LEDs } \\
\text { LCD } \\
\text { Speaker } \\
\text { Vibration Motor } \\
\text { WIFI Module }\end{array}$ & $\begin{array}{l}\text { Detector the Fault in } \\
\text { in the system } \\
\text { emergency } \\
\text { messages on the } \\
\text { LCD and Speaker } \\
\text { system } \\
\text { Turn on bed and } \\
\text { couch vibration }\end{array}$ & $\begin{array}{l}\text { ᄃ Red LEDs stay on } \\
\text { OJ LCD is displaying } \\
\text { Ju emergency } \\
\mathbb{U} \text { instructions } \\
\text { W. Speaking is } \\
\text { broadcasting } \\
\text { emergency } \\
\text { instructions } \\
\text { Vibrators are on } \\
\text { Locating the user's } \\
\text { address } \\
\text { Emergency personal } \\
\text { and emergency } \\
\text { contact has been } \\
\text { alerted }\end{array}$ \\
\hline
\end{tabular}

Fig 4. Designed System's Functionality

It explains our hardware, software and execution and every step in the proposed algorithm. The system will start as the power runs through it, at which point the system will wait for instructions. Once a fault is received into our microcontroller from the detectors, the system will inform the occupant immediately of the situation at hand. The program will repeat itself with no limitation until the occupant himself or emergency personnel resets the system.

Copyright $\odot$ Authors
Published online 07-August-2020

\section{B. Experiment Setup andImplementation}

We chose to use the Arduino IDE software, as it is an open sourced program and it is proved to be very efficient as well as user friendly. The environment was Microsoft 10 Pro with intel Core I7. Table VII illustrates the main component for the first experiment before the actual prototype was designed.

After the user turns on the system, the program on Arduino will check the sensory data in real time. This system will be always running and checking for emergency events. The sensory data are received by microcontroller simultaneously, and the microcontroller processes these signals based on the priority of each signal and then appropriate feedback (audio or tactile) will be sent by triggering the corresponding module (speaker, LEDs or vibration motors). The sensory data flow procedure is described in Fig 5.

Table VII Main Components Of Designed System
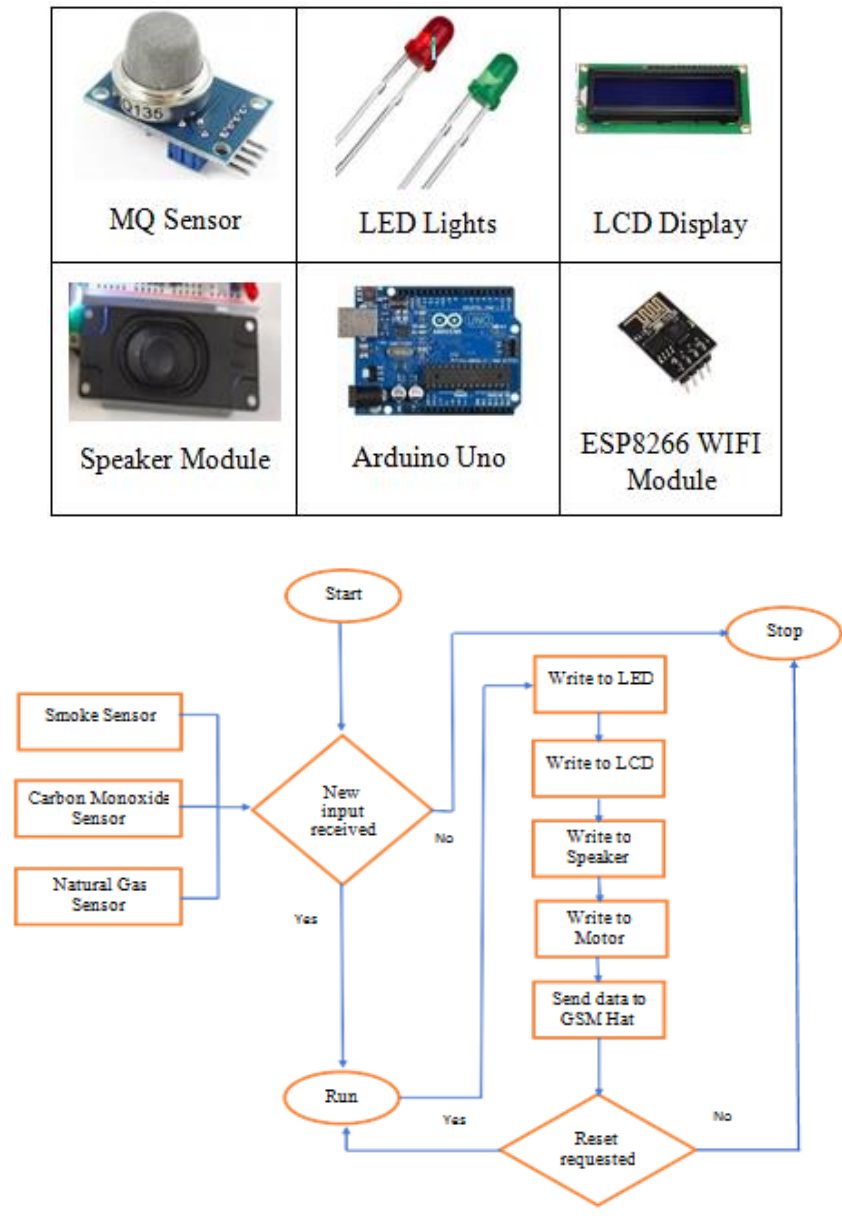

Fig 5. Sensory Data Flow Diagram 
The above implemented algorithm describes the sensory data processing. Upon the detection of high Smoke, carbon monoxide or natural gas values, our main program runs and creates five simultaneous responses that help the blind or deaf evacuate during an emergency situation. The input for the program is the detection of dangerous values by one of the three gas sensors: MQ2, MQ5, and MQ7. After the input is detected, the program runs and triggers the system response. The simultaneous responses include flashing LED lights, an emergency message "'Fire is detected, exit for safety", "Gas is detected, exit for safety", or "Carbon monoxide is detected, exit for safety") printed on the LCD screen, an emergency voice message heard on the speaker module, the function of vibrating motors placed under furniture and finally a text message sent out through the WIFI module. The message that will be sent to the caregivers or 911 will contain the name and address of the user. These responses are simultaneous. When the reset button is clicked, the program runs again, and the system response starts over again.

There are three analog pins on our Arduino microcontroller, which connect to the MQ2, MQ5 and MQ7 Gas sensors. All other components are assigned with the digital pins of the Arduino. Once the value of the Gas Sensor exceeds the value of the system response, the system is triggered writing to pins, activating the flashing lights and vibrating motors. The speaker plays the specific message for a specific amount of times. A specific text message is sent using the ESP8226 WIFI module. The designed assistive system is illustrated in Fig 6 .

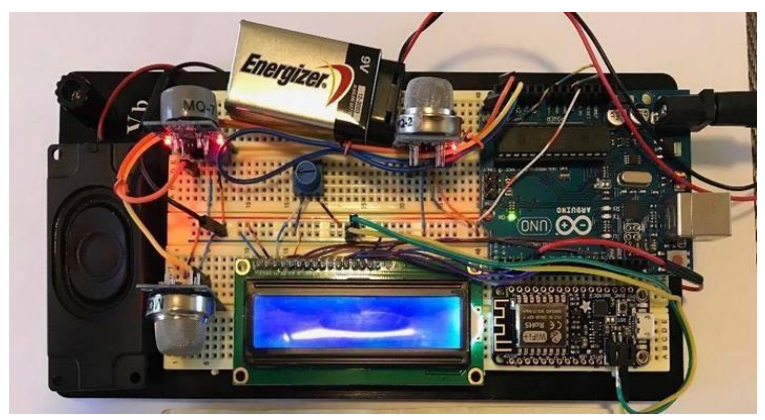

Fig 6. Hardware/Software Design of the FRIES. System

\section{EXPERIMENT}

\section{A. Testing Results and Analysis}

The entire system was tested and ran the main program expecting simultaneous responses. The sensors ran simultaneously. In Fig 7, we can notice that the three

Copyright $@$ A Authors sensors are working, and the readings can be seen on the LCD screen. In Fig 8, the Wi-Fi module is being tested to make sure that in case of the emergency, visually impaired and hearing-impaired individuals can exit the building rather than worrying about a phone call. This is very crucial.

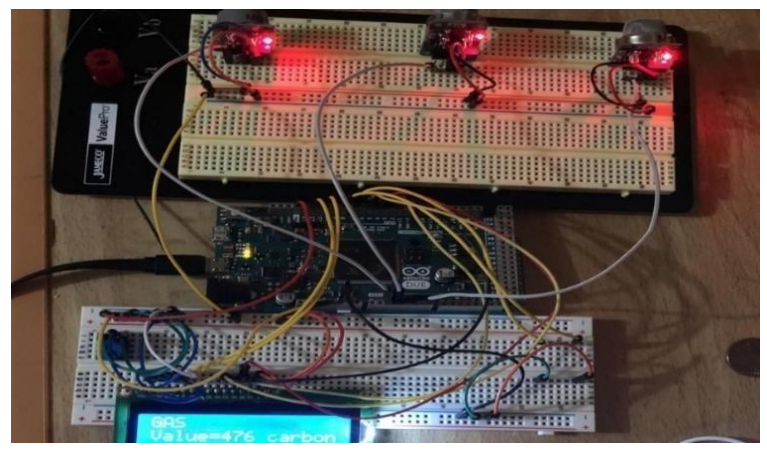

Fig 7. Testing the three Detectors

In order to ensure the safety, messages to caregivers and to 911 need to be sent. Text messages were sent using the ESP8266 Wi-Fi module. Fig 9 shows that the full systems function correctly with the speaker modules, LCD display and LEDs. Fig 10 shows the text message (output) on the user's cellphone. Similar message will be displayed on the LCD display and an audio message will be produced to the speaker. User's information will be sent as text message to 911 and to his/her emergency contacts or caregivers. In order to ensure the functionality, number of iterations were run.

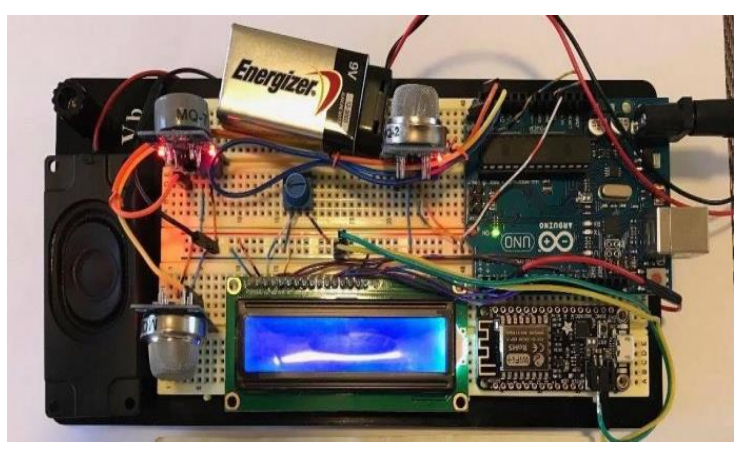

Fig 8. WIFI Module Testing 
IT in Industry, vol. 8, no.2, 2020

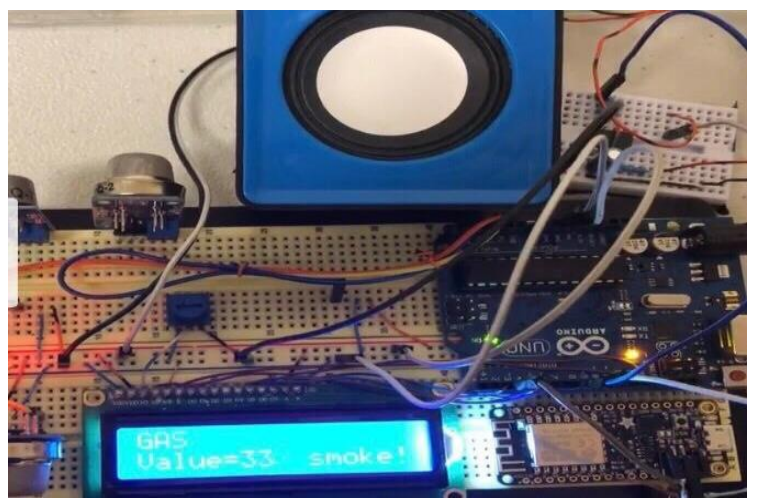

Fig 9. Testing the Entire System

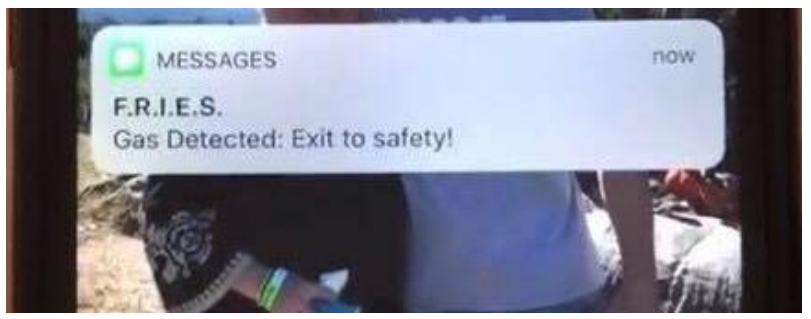

Fig 10. Representation of the Output on the User's End

As shown in above figures, the system was able to produce all the proper and expected responses to emergencies like natural gas leak, carbon monoxide leak and fire. The Wi-Fi module also worked as expected and the message was sent to the phone indicating an emergency.

We have run a number of iterations to ensure the efficiency of our system. This allowed us to make sure each component was working properly, and this also saved us time when conducting the complete system test. Fig 11 shows the sensors reading.

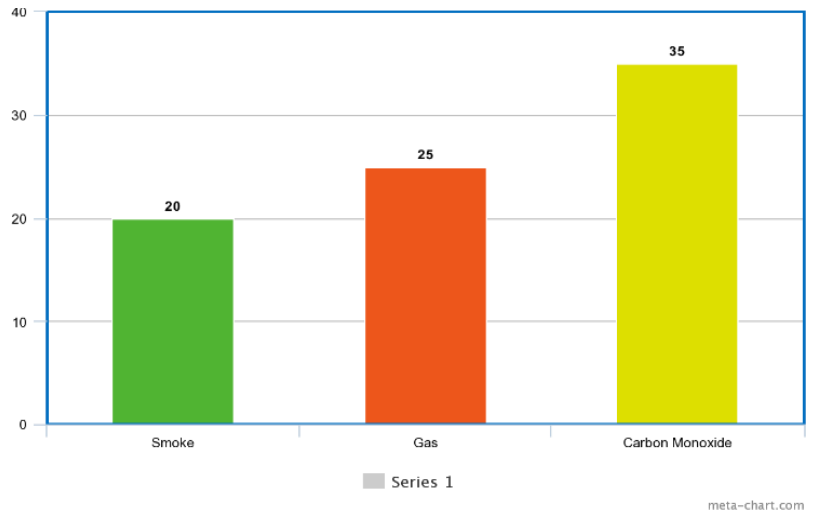

Fig 11. The Reading of Sensors
Published online 07-August-2020

These numbers were tested against the expected values and matched. It is very important that we get accurate results of the sensors. The system now is ready to be tested in a small designed home facility made of Plexiglas. Our custom-made PCB allowed the LED lights to power from outside of the Arduino Board and also were working in the Plexiglas facility.

There are a number of challenges that we faced before we test the system. We began by conducting a unit test of each component in respect to our microcontroller, which included the LED lights, gas sensors, speaker, WIFI module, vibrating motors and LCD display. We have run number of iterations to ensure the efficiency of our system. This allowed us to make sure each component was working properly, and this also saved us time when conducting the complete system test. During this stage of the test, we were able to diagnose different problems within our system and came up with different approaches. Issues that we faced included lose wire connections which caused the speaker to not function properly first time, inconsistency among values obtained by the sensors, and power issues as the Arduino Uno Microcontroller supplied $5 \mathrm{~V}$ volts. These issues were solved by rewiring the whole system and making our own customable PCB Board (this will be described in the next section). We also switched to the ESP8266 WIFI module.

\section{B. Testing Facility with The Custom-Made PCB}

After running a number of scenarios to test the function of each component: motor, speaker, screen, and red and white LED's, we were able to test the whole system in a small built facility to notice the complete functionality as one system. Our initial plan was to purchase LEGO's and build a testing facility with a room, restroom, and a living space. This mini apartment would have had wiring running through the LEGO pieces. However, we realized that by doing so there would be no clear visibility for the audience to see the wires running through the testing facility and become hard for the team to spot wiring issues immediately. We finally decided to build a plexiglass house for better visibility. Plexiglas is another name for cyanoacrylate sheets. This basically is a hard plastic sheet. There are three doors in the facility. One of them is entrance to the apartment, the other entrance is for the bedroom and lastly an entrance for the restroom.

The next step was to place the components in the test facility. We placed two white LEDs at every door. Along with white LEDs, we placed one red LED at the exit door 
IT in Industry, vol. 8, no.2, 2020

of the testing facility to signal an emergency so that the individual can exit the apartment. There are also two motors placed in the testing facility. One in the bed and the other in the couch. This is done so that in case of fire, carbon monoxide leak, or gas leak, the hearing or visually impaired individuals can wake up if they are sleeping. The motors are connected directly to the couch and bed once we receive them. The Fig 12 shows the testing facility. We decided to use the custom PCB board to support our system mechanically by connecting our devices to the board electrically with wires. The custom power distribution board also helped us to decrease the stress on the microcontroller. In order to increase the efficiency of our product, we have used the 555 chip along with a capacitor and three resistors which are one 220 -ohm resistor and two 10K-ohm resistors. Two 10Kohm resistors are used to create a delay time for flashing white LED lights and a 220 -ohm resistor is used to adjust the power that is given to the lights to prevent lights from getting burned off. Fig 13 illustrates the custom-made PCB.

As we can see in Fig 14, the testing facility is complete. It demonstrates how our system would look in real life scenarios. The vibrating motors were attached to the couch as well as the bed, which both couch and bed were suspended by springs to amplify the vibration so it can show how this system can operate in real life scenario.

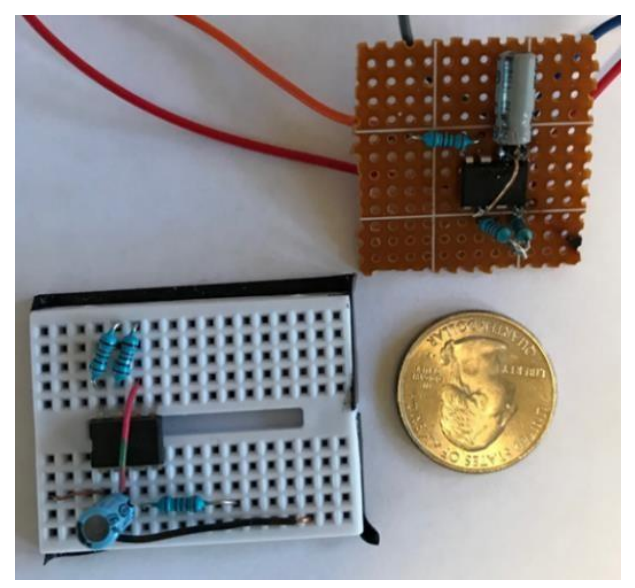

Fig 12. The Testing Facility
Published online 07-August-2020

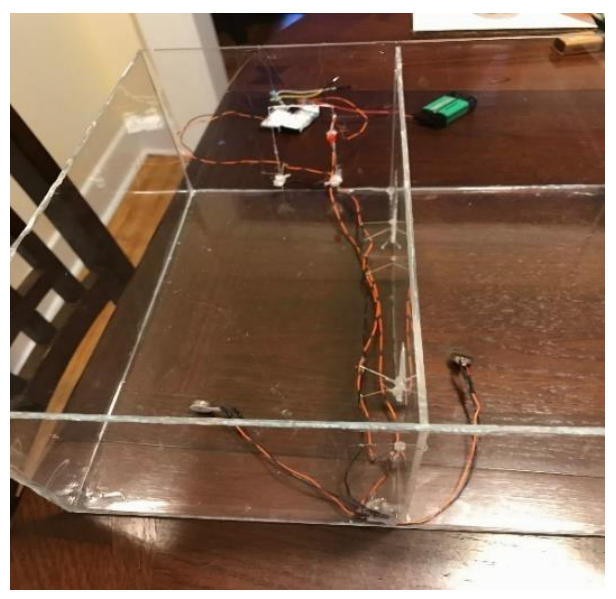

Fig 13. The Custom-Made PCB

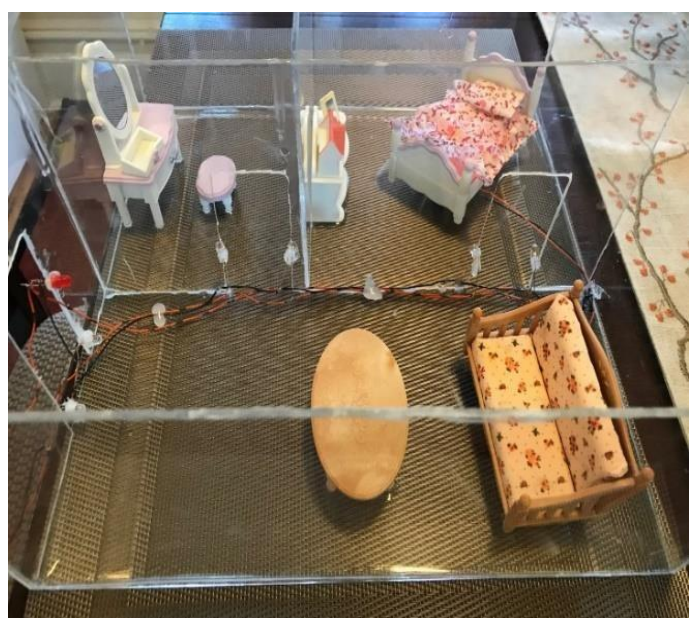

Fig 14. Complete Tested Model

\section{Power Consumption}

We aim to design a system for low-power operations. Therefore, it is important to select the materials with minimal power consumption and could still meet all our device functionality requirements. For example, the WiFi module we chose is ESP8266, which only consumes $561 \mathrm{~mW}$ under $802.11 \mathrm{~b}$ standard. An estimation of the power consumption is shown in Table VIII below. This calculation is based on the running mode when all sensors are triggered. The power will consume much less when the system is in idle mode. There were four major sources of power consumption, which are the sensors, speaker, motors, and the wireless communication. Our power supply is going to be uninterruptible since we are using a 9-volt battery that will be able to power the system. 
IT in Industry, vol. 8, no.2, 2020

Table VIII Power Consumption Of Designed System

\begin{tabular}{c|l|c}
\hline \hline Parts & \multicolumn{1}{|c}{ Specifications } & $\begin{array}{c}\text { Rated Power } \\
\text { Consumption }\end{array}$ \\
\hline Microcontroller & \multicolumn{1}{|c}{ Arduino Uno } & $232.5 \mathrm{~mW}$ \\
\hline Speaker & $\begin{array}{l}\text { CQRobot Arduino } \\
\text { Speaker }\end{array}$ & $2000 \mathrm{~mW}$ \\
\hline WIFI Module & \multicolumn{1}{|c}{ ESP8266 } & $561 \mathrm{~mW}$ \\
\hline Motors & $\begin{array}{l}\text { Two Robotics Vibrating } \\
\text { motors }\end{array}$ & $1000 \mathrm{~mW}$ \\
\hline Sensors & $\begin{array}{l}\text { Smoke, Carbon and Gas } \\
\text { sensor }\end{array}$ & $1850 \mathrm{~mW}$ \\
\hline LCD display & \multicolumn{1}{|c}{$16 \times 2$ Display } & $9 \mathrm{~mW}$ \\
\hline LEDs & \begin{tabular}{l} 
Bright Red Light \& \\
\cline { 2 - 3 }
\end{tabular} & $10 \mathrm{~mW}$ \\
\hline \hline & Tlashing White Light \\
\hline
\end{tabular}

\section{Real-World Scenario}

FRIES is an emergency system that warns and assists individuals regardless of their needs and even goes as far as alerting not only emergency personnel but also people's emergency contacts. In the real-world scenario, the system will be operated as follows: 1) the system will be powered on by users manually and FRIES goes into a mode of real-time running and checking for emergency events; 2) Once an event is detected, the LED's will light up, the speaker will inform the occupant of the emergency, the LCD screen will display

emergency instructions to the occupant, vibration motors located in every bed and couch will assist in fast warning for individuals with the visually and hearing impaired; 3) Emergency personnel will be notified to assist the occupant with the emergency preparations with evacuation plan; 4) FRIES will send a message to the emergency response switchboard alerting them of the: Address, Situation (Fire Detector, Carbon Monoxide Detector, Natural Gas Detector), Condition of the occupant (Visually Impaired or Hearing Impaired); 5) The system will also send a message to the listed emergency contact of the occupant.

To deploy this system to the living environment, there are three considerations. First, the living environment must have reliable Wi-Fi access, to ensure that FRIES can send messages to emergency contacts. Second, the system will be improved with a modular and user-friendly design so that it is easy to install it in the real living environment. Third, the system will be scaled and adapted to a large living environment, such as rehabilitation and nursing center for the disabilities.

Copyright $\odot$ Authors
Published online 07-August-2020

\section{COMPARISON AND DISCUSSION}

The objective of this study is to overcome the limitation of the reviewed systems by designing a new affordable system that supports missing features in an effective and autonomous design. Table IX presents a comparison of previous systems that were reviewed in section 2; this comparison is based on both the users' needs and the engineers' perspectives.

The factors in Table IX were chosen based on the literature

survey we have done. The unavailability of these features can negatively influence the performance and the purpose of the systems. The main concerns from the users would be the cost, the range of the service, and the accessibility of the service. The main concerns from the engineers are the types of the sensors, the range of the detection, used techniques, detection type, response type, and the emergency contact service. More factors can be added to Table IX, and some of the listed factors can be mutual as requirements of both users and engineers. The abovementioned features and parameters can explain the limitation and the need for a complete and affordable system that can completely serve these individuals, in addition to the fact that there is a lack of research work that addresses the needs of the disabled people.

The design of the system has several limitations. For example, [8 and 9] are wearable systems that require the system to be worn or attached to the user, so that user can receive the notifications or alerts. In addition, portable systems such as [10 and 11] require the presence of the user to be in the same room, and near to the device to get notification. Their usage is limited to one room. Furthermore, approximately $60 \%$ of the reviewed systems are limited in their response type which can be either tactile or audio. Thus, these systems are not applicable for users who are visually and hearing impaired.

Roughly none of the reviewed techniques fully satisfied the benchmark table requirements. For instance, the service type of proposed system in [7] depends on the user's presence. The system is accessible to visually and hearing-impaired people. However, it only detects fire. The response type is only audible and text messages on the cellphone. Thus, if the phone is not close to the user, he/she will not be able to hear or read the notifications. Caregivers and relatives will not get notified in case of emergency. Hence, the emergency services cannot be provided for the user, such as 911 services. 
Based on the benchmark in Table IX, we suggest that the its features and the ability to satisfy the needs of the user. proposed system stands outperforms other systems due to

Table IX Comparison Between The Proposed System And Existing System Based On The User's Needs

\begin{tabular}{|c|c|c|c|c|c|c|c|c|c|c|c|c|c|c|}
\hline \multirow{3}{*}{ System } & \multicolumn{5}{|c|}{ User's Perspective } & \multicolumn{7}{|c|}{ Engineer's Perspective } & & \\
\hline & \multirow[t]{2}{*}{ Cost } & \multicolumn{2}{|c|}{ Service Range } & \multicolumn{2}{|c|}{ Accessibility for } & \multirow{2}{*}{$\begin{array}{l}\text { Type of } \\
\text { Sensors }\end{array}$} & \multirow{2}{*}{$\begin{array}{l}\text { Type of } \\
\text { Usage }\end{array}$} & \multirow{2}{*}{$\begin{array}{l}\text { Used Protocols/ } \\
\text { Techniques }\end{array}$} & \multicolumn{3}{|c|}{ Detection } & \multirow{2}{*}{$\begin{array}{c}\text { Response } \\
\text { Type }\end{array}$} & \multicolumn{2}{|c|}{$\begin{array}{c}\text { Emergency } \\
\text { Contact Service }\end{array}$} \\
\hline & & \begin{tabular}{|l|} 
One \\
Room
\end{tabular} & \begin{tabular}{|l|} 
Complete \\
Property
\end{tabular} & \begin{tabular}{|c|} 
Visually \\
Impaired
\end{tabular} & \begin{tabular}{|c|} 
Hearing \\
Impaired
\end{tabular} & & & & Fire & \begin{tabular}{|c|} 
Carbon \\
Monoxide
\end{tabular} & Gas & & \begin{tabular}{|c|} 
SMS to \\
Caregivers
\end{tabular} & $\begin{array}{c}\text { SMS } \\
\text { to } \\
911\end{array}$ \\
\hline [1] & - & & $\checkmark$ & $\checkmark$ & - & $\begin{array}{c}\text { Vision } \\
\text { Sensors }\end{array}$ & Pilot Stage & $\begin{array}{c}\text { Deep convolutional } \\
\text { neural network }\end{array}$ & $\checkmark$ & - & - & Audio & No & No \\
\hline [6] & - & $\checkmark$ & - & - & $\checkmark$ & \begin{tabular}{|l} 
TurtleBotkit \\
(3D \\
sensors)
\end{tabular} & Pilot Stage & $\begin{array}{l}\text { SLAM algorithm, } \\
\text { Haptic } \\
\text { Communication }\end{array}$ & - & - & - & Tactile & No & No \\
\hline [7] & - & \begin{tabular}{|l|}
$\checkmark$ Note: \\
the \\
location \\
$\quad$ is \\
dependon \\
the phone \\
existence
\end{tabular} & - & $\checkmark$ & $\checkmark$ & \begin{tabular}{|c|} 
ZIPATO \\
gateway, a smoke \\
sensor, a flood \\
sensor, and a gas \\
sensor
\end{tabular} & Pilot Stage & $\begin{array}{l}\text { Zwave protocol } \\
\text { and cloud server }\end{array}$ & $\checkmark$ & - & $\checkmark$ & $\begin{array}{l}\text { Audio and } \\
\text { Text } \\
\text { Messages }\end{array}$ & No & No \\
\hline [8] & low & $\begin{array}{c}\checkmark \text { Note: } \\
\text { it is } \\
\text { wearable } \\
\text { device }\end{array}$ & - & - & $\checkmark$ & $\begin{array}{c}\text { Smoke } \\
\text { detector and } \\
\text { vibration } \\
\text { motors }\end{array}$ & $\begin{array}{c}\text { Deployment } \\
\text { stage }\end{array}$ & $\begin{array}{l}\text { Radio frequency } \\
\text { communications } \\
\text { and Bluetooth }\end{array}$ & $\checkmark$ & $\checkmark$ & $\checkmark$ & $\begin{array}{l}\text { Tactile and } \\
\text { lighting } \\
\text { (LED) }\end{array}$ & No & No \\
\hline [9] & $\$ 224.25$ & $\begin{array}{c}\checkmark \text { Note: } \\
\text { it is } \\
\text { wearable } \\
\text { device }\end{array}$ & - & - & $\checkmark$ & $\begin{array}{c}\text { Smoke } \\
\text { detector and } \\
\text { vibration } \\
\text { motors }\end{array}$ & $\begin{array}{c}\text { Deployment } \\
\text { stage }\end{array}$ & $\begin{array}{l}\text { Radio frequency } \\
\text { communications }\end{array}$ & $\checkmark$ & - & $\checkmark$ & $\begin{array}{c}\text { Audio, } \\
\text { visual, } \\
\text { and } \\
\text { Tactile }\end{array}$ & No & No \\
\hline [10] & $\begin{array}{c}\$ 178.57 \\
\text { to } \\
\$ 195.95\end{array}$ & $\checkmark$ & - & $\checkmark$ & $\checkmark$ & $\begin{array}{c}\text { Smoke } \\
\text { detectors }\end{array}$ & $\begin{array}{c}\text { Deployment } \\
\text { stage }\end{array}$ & $\begin{array}{l}\text { Radio frequency } \\
\text { communications }\end{array}$ & $\checkmark$ & - & $\checkmark$ & $\begin{array}{l}\text { Tactile and } \\
\text { lighting } \\
\text { (LED) }\end{array}$ & No & No \\
\hline [11] & $\$ 142.65$ & $\checkmark$ & - & - & $\checkmark$ & $\begin{array}{c}\text { smoke and heat } \\
\text { alarms }\end{array}$ & $\begin{array}{c}\text { Deployment } \\
\text { stage }\end{array}$ & $\begin{array}{l}\text { Radio frequency } \\
\text { communications }\end{array}$ & $\checkmark$ & - & $\checkmark$ & Tactile & No & No \\
\hline $\begin{array}{c}\text { Proposed } \\
\text { System }\end{array}$ & $\$ \$ 115$ & & $\checkmark$ & $\checkmark$ & $\checkmark$ & \begin{tabular}{|c|} 
Fire, Carbon \\
Monoxide, Gas \\
detectors and \\
vibration motors
\end{tabular} & Pilot Stage & WI-FI & $\checkmark$ & $\checkmark$ & $\checkmark$ & $\begin{array}{c}\text { Audio, } \\
\text { Visual, Text } \\
\text { Messages, } \\
\text { Tactile and } \\
\text { lighting }\end{array}$ & Yes & Yes \\
\hline
\end{tabular}

\section{ACTUAL SETUP OF REAL IMPLEMENTATION}

The FRIES system is designed to help individuals when they are most vulnerable. The system needs to have a long-life cycle, especially since this system needs to be hardwired meaning it cannot be replaced at will. Seeing current fire awareness systems have a battery life span of 10 years, we expected our system to have a life spam of at least 20 years. This will be achieved from the low current usage and the battery backup that we will introduce to the system for current outage situations. Besides, we need to make it a reliable product while keeping the cost down. For our system were creating custom power management systems and relay switches/boards, this means that we can replace our microcontroller with a simpler circuit switchboard.

In an actual system, several improvements should be considered: 1) More sensors will be added to increase the scalability of the system; 2) Sensors will be designed with wireless connectivity by incorporating the WiFi module. The sensors can send signals to the main central controller 
via WiFi; 3) Vibrating motors will be designed with wireless connectivity and they receive $120 \mathrm{~V}$ input from the wall outlet. So that it can receive enough power to vibrate the real bed mattresses or couches; 4) Remotely access to power on and off the system in case the system needs to reboot and reset to default settings.

As we can see in Table $\mathrm{X}$, the material cost of this actual system ended up for $\$ 303.5$ if it is installed in a typical 3bedroom, 2-bathroom single family house. Our goal is to provide a responsive system that can be affordable to visually and hearing-impaired people, in addition to they will be more independent.

Table X System's Estimated Cost For Primary Pieces

\begin{tabular}{ccc}
\hline \hline Count & Hardware & $\frac{\text { Cost }}{\$ 35}$ \\
\cline { 1 - 2 } 2 & Arduino Kit & $\$ 10$ \\
10 & CQRobot Arduino Speaker 3W & $\$ 69.5$ \\
3 & ESP8266 WIFI Module & $\$ 15$ \\
3 & MQ2 Gas Sensor & $\$ 15$ \\
3 & MQ5 Gas Sensor & $\$ 15$ \\
3 & MQ7 Carbon Monoxide Sensor & $\$ 105$ \\
5 & VibratingMotor for Bed & $\$ 25$ \\
2 & PCB Blank Board & $\$ 14$ \\
& 9V Batteries & $\$ 303.5$ \\
\hline \hline
\end{tabular}

\section{CONCLUSION}

This research proposes a new emergency alert system called FRIES, to ensure that the visually impaired and hearing- impaired individuals will be notified of an emergency and can take safety measures. This system provides a safe living environment to the visually impaired and hearing-impaired individuals. Emergency authorities are also informed about the disabled persons' condition along with the individuals close family members or listed emergency contact. The main advantage of this system is two-fold: 1) The estimated cost for the project proves that this comprehensive emergency alertsystem is affordable; 2) It can be installed in any living environment, whether it is a private house or an apartment. Living in a specific desired location should not be an obstacle if you are with a hearing or visual disability. However, this system is still a prototype which has limitations in scalability. In the future, we will increase the scalability by interfacing it with many different types of sensors. Besides, we will make this system more user friendly. For example, access remotely to power on and off the system in case the system needs

Copyright $\odot$ Authors to reboot and reset to default settings. In addition, we will use LEGO or 3D printing to make a modular design of the prototype. Another extension to this work is to use an object detection algorithm to detect the size of the fire and recorded within the sent information to the emergency personnel. Finally, predicative market analysis might be used to forecast the market demand of this system [15].

Additionally, integrating artificial intelligence (AI) to assist the visually and hearing impaired is an important future direction [16]. Massaro et al proposed a health resource management system using multiplayer perception (MLP) and artificial neural network (ANN) to trigger alert by analyzing the real-time and historical patient data [17]. Another work is proposed to detect patient health status using a long short-term memory (LSTM) neural network [18]. In the future, we can analyze the health data from the visually and hearing impaired using the AI techniques in real time. This allows us to build a comprehensive emergency system to provide safety for the visually and hearing impaired, in case of fire, carbon monoxide, natural gas leak and other health emergency issues.

\section{REFERENCES}

[1] Kong B., Lim K., Kwon J. (2019) Fire Detection Using DCNN for Assisting Visually Impaired People in IoT Service Environment. In: De La Prieta F., Omatu S., Fernández-Caballero A. (eds) Distributed Computing and Artificial Intelligence, 15th International Conference. DCAI 2018. Advances in Intelligent Systems and Computing, vol 800.Springer, Cham

[2] Milke, J. A. (2010). History of smoke detection: a profile of how the technology and role of smoke detection has changed. A report formulated for Siemens Industry, Inc, Building Technologies Division, Fire Life Safety Unit, By Department of Fire Protection Engineering, University of Maryland.

[3] http://jerusalemhand.com/2014/06/19/fire-naturaldisaster/, "Natural Disasters" Jerusalemhand, an international organization that for the rehabilitated [Online access: 10/28/2019].

[4] K. Muhammad, J. Ahmad, I. Mehmood, S. Rho and S. W. Baik, "Convolutional Neural Networks Based Fire Detection in Surveillance Videos," in IEEE Access, vol. 6, pp. 18174-18183, 2018, doi: 10.1109/ACCESS.2018.2812835.

[5] Elmannai, Wafa M., and Khaled M. Elleithy. "A highly accurate and reliable data fusion framework 
IT in Industry, vol. 8, no.2, 2020

for guiding the visually impaired." IEEE Access 6 (2018): 33029-33054.

[6] Furuhashi, Michihiko, et al. "Haptic communication robot for urgent notification of hearing-impaired people." 2016 11th ACM/IEEE International Conference on Human-Robot Interaction (HRI). IEEE, 2016, pp. 429-430.

[7] Ciabattoni, Lucio, et al. "Hear to see-See to hear: a Smart Home System User Interface for visually or hearing-impaired people." 2018 IEEE 8th International Conference on Consumer ElectronicsBerlin (ICCE-Berlin). IEEE, 2018.7.

[8] Wright, John Richard. (2014) "Tactile and Visual Smoke Detector System." U.S. Patent Application No. 14/259,679.

[9] LIFETONEHLAC150 Alarm Clock Manual, https://www.manualslib.com/manual/765288/Lifeto ne- Hlac150.html?page=2\#manual, [online access: 10/1/2019]

[10] Bellman Visit Pager Receiver for the Hard of Hearing, https://www.amplifiedtelephones.co.uk/bellmanvisit-pager-receiver-for- the-hard-of-hearing.html, [online access: 10/2/2019]

[11] Aico Ei176RF Smoke Alarm User Manual, https://manualszoom.com/manuals/householdappliance/smoke- alarm/aico/aico-ei176rf-smokealarm.html [online access: 10/2/2019]

[12] https://store.arduino.cc/usa/arduino-uno-rev3 [online access: 04/18/2020]

[13] https://www.canakit.com/raspberry-pi-44gb.html?cid=usd\&src=raspberrypi [online access: 04/18/2020]

[14] https://www.educba.com/raspberry-pi-vs-arduino/ [online access: 04/17/2020]

[15] Czwajda L., Kosacka-Olejnik M., Kudelska I., Kostrzewski M., Sethanan K., Pitakaso R., 2019, Application of prediction markets phenomenon as decision support instrument in vehicle recycling sector, LogForum, Vol. 15, Issue 2, pp. 265-278. DOI: 10.17270/J.LOG.2019.329

[16] Al-Muqbali, F., Al-Tourshi, N., Al-Kiyumi, K., \& Hajmohideen, F. (2020, April). Smart Technologies for Visually Impaired: Assisting and conquering infirmity of blind people using AI Technologies. In 2020 12th Annual Undergraduate Research Conference on Applied Computing (URC) (pp. 1-4). IEEE.

[17] Massaro, A., Maritati, V., Savino, N., Galiano, A., Convertini, D., De Fonte, E., \& Di Muro, M. (2018). A Study of a health resources management platform
Published online 07-August-2020

integrating neural networks and DSS telemedicine for homecare assistance. Information, vol. 9, issue 7, 176.

[18] Massaro, A., Maritati, V., Giannone, D., Convertini, D., \& Galiano, A. (2019). LSTM DSS automatism and dataset optimization for diabetes prediction. Applied Sciences, vol. 9, issue 17, 3532. 